\title{
El proceso negociador en el derecho internacional contemporáneo: de la elaboración de acuerdos a la solución de controversias internacionales(*)
}

\section{POR LEOPOLDO M. A. GODIO $(* *)$}

\begin{abstract}
Sumario: I. Introducción.- II. Los procedimientos diplomáticos y la negociación como proceso idóneo de solución de controversias internacionales.- III. El desafío de las negociaciones contemporáneas y su situación espacio-temporal. Del impasse diplomático a la solución concertada y sostenible.- IV. La negociación en la jurisprudencia de la Corte Internacional de Justicia.- V. La "obligación de negociar" en la Corte Permanente de Justicia Internacional y la Corte Internacional de Justicia.- VI. La interpretación de Corte Internacional de Justicia respecto de la obligación de negociar el acceso al océano Pacífico.- VII. Consideraciones sobre la buena fe aplicada a la negociación como solución de controversias.- VIII. Reflexiones finales.- IX. Bibliografía.
\end{abstract}

Resumen: el proceso negociador comprende un último objetivo: promover la cooperación y coordinación internacional, además de mantener o restaurar la paz y la seguridad internacionales. De entre los diferentes medios de solución pacífica, la negociación es la elección principal de los Estados para regular y conducir las relaciones internacionales, ya que se distingue de otros medios por carecer de la participación de terceros y reforzar el concepto del consentimiento estatal. Definitivamente, la negociación es fundamental para la diplomacia y la búsqueda de objetivos de política exterior. Con este marco teórico, analizaremos la negociación y su interpretación por la Corte Internacional de Justicia, incluyendo su examen sobre la llamada "obligación de negociar".

(*) El presente trabajo constituye un desarrollo de las ideas personales del autor, expresadas en el examen de oposición de aspirantes a Profesor Titular de Derecho Internacional Público de la Facultad de Derecho de la Universidad de Buenos Aires, el 22 de octubre de 2018.

(**) Abogado, Magíster en Relaciones Internacionales y Doctor, tesis Sobresaliente y recomendada al "Premio Facultad" (Universidad de Buenos Aires). Prof. de Derecho Internacional Público. Miembro Titular de la Asociación Argentina de Derecho Internacional. Miembro Consultor y Consejero del Consejo Argentino para las Relaciones Internacionales y Secretario del Instituto de Derecho Internacional de la Academia Nacional de Derecho y Ciencias Sociales de Buenos Aires, entre otras instituciones. 
Palabras claves: solución pacífica de controversias - negociación - proceso negociador - obligación de negociar

The negotiating process in contemporary international law: from the elaboration of agreements to the resolution of international disputes

Abstract: the negotiation process' involves a last objective: promote international cooperation and coordination, also maintain or restore international peace and security. Among the different means of pacific settlement of disputes, negotiation is the main choice of States to regulate and conduct international relations, since it is distinguished from other means, because it lacks the participation of third parties and reinforces the concept of State consent. Definitely, the negotiation is central to diplomacyand the pursuit offoreign policyobjectives. With this theoretical framework we will analyze the negotiation and its interpretation by the International Court of Justice, including its examination of the so-called "obligation to negotiate".

Keywords: pacific settlement of disputes - negotiation - negotiation process obligation to negotiate

\section{Introducción}

El devenir de las interacciones entre Estados —entendida desde el paradigma del realismo en las relaciones internacionales- conceptualizó tradicionalmente al mundo como un escenario de permanentes conflictos, en el cual los sujetos del sistema actuaban en interés propio "por el poder y la paz", cuya seguridad y cooperación eran garantizados, temporalmente, por la voluntad e interés de las Potencias hegemónicas, quienes establecían las normas estructurales de división de poder, con predominio de la autoridad militar (Waltz, 2006, p. 122 y ss.).

Sin embargo, en la segunda mitad del siglo XX, las relaciones internacionales adoptaron una dinámica interdependiente debido a la multiplicación y atomización de las controversias que exhibieron, adicionalmente, distintos niveles de desarrollo, características particulares y hasta vinculaciones complejas "imperfectamente relacionadas", presentando tres elementos determinantes: 1) canales múltiples que conectan las sociedades; 2) ausencia de jerarquías; y 3) pérdida de relevancia de la fuerza militar a nivel regional (Keohane, 1988, p. 41).

En este contexto, la utilización de los distintos métodos pacíficos de solución de controversias resultó una contribución a la estabilidad de las relaciones entre los Estados, tal como se observa en el incremento de su utilización y diversidad, especialmente ante el aumento de nuevos foros de solución judicial en tribunales permanentes institucionalizados, además de superar los desconfianzas que anunciaban - a finales del siglo XX - la fragmentación del derecho internacional 
EL PROCESO NEGOCIADOR EN EL DERECHO INTERNACIONAL CONTEMPORÁNEO: DE LA ELABORACIÓN DE ACUERDOS A LA SOLUCIÓN DE CONTROVERSIAS INTERNACIONALES

- LEOPOLDO M. A. GODIO (PP. 495-526)

(Godio, 2014, pp. 287-336), como consecuencia de potenciales decisiones contradictorias en controversias. Finalmente, la temida superposición no ocurrió (Caminos, 2013, pp. 55-64).

Sin perjuicio de las históricas clasificaciones doctrinarias que diferencien a los métodos en diplomáticos y judiciales, también es posible establecer un criterio que distinga: 1) los procedimientos diplomáticos; 2) el procedimiento arbitral; 3) la solución judicial en tribunales permanentes institucionalizados; y 4) las soluciones ante organismos internacionales.

En la primera de las categorías señaladas aparecen medios como la negociación, los buenos oficios, la mediación, la investigación y la conciliación, todas opciones aptas para alcanzar la solución pacífica de las controversias internacionales (Sørensen, 1994, p. 628). De ellas la negociación se distingue, particular e inicialmente, por tratarse del único método que no requiere la intervención de un tercero para encontrar un resultado satisfactorio que ponga fin a la disputa.

Por esta razón, sumado también a su importancia histórica, el presente trabajo propone examinar el proceso negociador y su rol como medio de solución, cuestión que además presenta una renovada actualidad luego del debate generado respecto de la llamada "obligación de negociar", recientemente considerada por la Corte Internacional de Justicia (CIJ), en la controversia entre Bolivia y Chile, decidida el $1^{\circ}$ de octubre de 2018, a la cual dedicaremos particular referencia para, finalmente, ofrecer nuestras reflexiones al respecto.

\section{Los procedimientos diplomáticos y la negociación como proceso idóneo de solución de controversias internacionales}

La esencia de la negociación consiste en examinar y tratar un tema, argumentativa y razonadamente, con distintos niveles de autoridad, con el fin de obtener un entendimiento o un acuerdo en común. Según Hakapää existen dos modos básicos de negociación en las relaciones internacionales: 1) la realizada como codificación y desarrollo progresivo del derecho internacional y 2) aquella utilizada como medio de solución - transitoria o definitiva - para una controversia (Hakapää, 2012, párr. 1).

En la lógica de las negociaciones, independientemente de la clasificación anterior, las consultas aparecen como una clase embrionaria dentro de las posibilidades disponibles para las partes, aunque también podría afirmarse que anteceden a estas, ya que suelen ser utilizadas para compartir información o realizar intercambios de carácter preliminar, tal como lo prevé el marco referencial genérico - no exhaustivo - de la Asamblea General en su Resolución 53/101, del 8 de diciembre de 1998, referida a los Principios y Directrices para las Negociaciones 
Internacionales, que reconoce el rol destacado de las negociaciones realizadas de modo constructivo y efectivo para alcanzar los propósitos de la Carta de las Naciones Unidas, así como contribuir a una administración pacífica de las relaciones internacionales, la solución pacífica de controversias y la creación de nuevas normas de conducta vinculantes.

Lo anterior resulta compatible, en una concepción amplia, con el criterio establecido por la Corte Permanente de Justicia Internacional (CPJI) en el caso $\mathrm{Ma}$ vrommatis, al caracterizar a la negociación como el procedimiento legal y administrativo mediante el cual los gobiernos - en el ejercicio de sus poderes- conducen sus relaciones, incluyendo la discusión, el arreglo y la solución de las controversias internacionales (1) (Corte Permanente de Justicia Internacional, 1924, pp. 62-63).

En cuanto a su materialización, las negociaciones se desarrollan a través de comunicaciones directas, habitualmente canalizadas por los medios diplomáticos oficiales - bajo responsabilidad de los Ministros de Relaciones Exteriores o los agentes autorizados por aquellos- aunque nada impide su realización personal por los Jefes de Estado o de Gobierno (Seara Vázquez, 2005, p. 343). El progreso de las negociaciones puede avanzar con distintos niveles de formalidad y publicidad, si la situación lo requiriese, habilitando una flexibilidad que permite -en una situación óptima de las relaciones recíprocas- una conducción eficaz para discutir las diferencias en forma amplia y franca.

A pesar de que los grados de formalidad o informalidad -más propio en los procesos bilaterales - suelen presentarse como aspectos auxiliares o secundarios de una negociación (por ejemplo, el establecimiento de la agenda o un calendario de negociaciones, el seguimiento de una hoja de ruta o de un programa de trabajo), también pueden obedecer, eventualmente, al intento para que las declaraciones formuladas por una $\mathrm{u}$ otra parte no resulten vinculantes ni puedan considerarse como definitivas (Davérède, 2012, párrs. 2 y 11).

Respecto a la "confidencialidad" de una negociación, aquella no debe ser equiparada al "secreto". Lo anterior no debe confundirse con él. Sobre este último, Davérède afirma que se ha utilizado en más de un sentido pero que, en general, este carácter surge cuando se realizan en lugares aislados y sin informar a posibles interesados, individuos o entidades, con el objeto que no conozcan el curso de las deliberaciones o evitar la injerencia de sectores sociales con intereses creados. El concepto "secreto" debe diferenciarse de "confidencial" e "informal", ya que el

(1) Cfr. Mavrommatis Palestine Concessions (Greece v. United Kingdom), Judgment of 30 August 1924, Objection to the Jurisdiction of the Court, P.C.I.J., Series A, No. 2 (pp. 62-63). 
EL PROCESO NEGOCIADOR EN EL DERECHO INTERNACIONAL CONTEMPORÁNEO: DE LA ELABORACIÓN DE ACUERDOS A LA SOLUCIÓN DE CONTROVERSIAS INTERNACIONALES

primero se refiere - generalmente- al carácter de todo el proceso, al tiempo que la "confidencialidad" puede utilizarse en documentos oficiales, con límites o plazos menores, lo que denota un menor grado respecto del anterior - sin perjuicio de la connotación que posee el término-, por lo que es posible anoticiar la existencia de una negociación, cuyo desarrollo es confidencial, al tiempo que ello no ocurre así con los procesos secretos, tal como ocurrió con las negociaciones de desarme entre los EE. UU. y la ex URSS, donde ambos intercambiaron información sobre inventarios de arsenales, datos que mantuvieron en secreto a sus propios ciudadanos. No obstante, el autor reconoce que las "negociaciones secretas" han sido identificadas, históricamente, con las prácticas caracterizadas por la intriga y el soborno, hoy superada por la diplomacia parlamentaria. Actualmente, muchas circunstancias de carácter local e internacional han contribuido a una mayor transparencia en las negociaciones internacionales, ya sea por iniciativa de Estados, organizaciones internacionales y la opinión pública, canalizada a través de las ONG y los medios de prensa, aunque no existe norma convencional alguna que lo prohíba, debido a que se trata de una actividad sujeta únicamente a la voluntad de las partes siempre que no afecte derechos de terceros ni viole una norma de ius cogens (Davérède, 2012, párrs. 1-3 y 9-12).

Por lo anterior es posible advertir que los distintos niveles de formalidad y publicidad - de acuerdo con la conveniencia para las partes- es comprendido como parte del intercambio directo de la negociación y que, según Rousseau, representa una de las claves que otorga ventaja a la diplomacia directa, junto con la ductilidad y discreción que le caracteriza, aunque reconoce posibles límites para su eficacia (Rousseau, 1966, p. 485). Idéntica valoración reconoce Hakapää al afirmar que la negociación evidencia cualidades ideales, ya que las partes solo deben disponer solamente del tiempo y el espacio necesario para debatir (Hakapää, 2012, párr. 20).

Esta adaptabilidad según las necesidades -en tanto proceso negociador en sí mismo, como también utilizado como medio de libre elección eficaz de una controversia - también es observada en la Declaración de Manila sobre el Arreglo de Controversias Internacionales, que direcciona a los Estados hacia una negociación significativa, con el fin de llegar a una pronta solución aceptable para las partes. La libertad en la elección de medios debe orientarse, de buena fe, hacia aquel más apropiado de común acuerdo para resolver la controversia, tal como lo ha destacado la CIJ el caso referido al incidente aéreo de 10 de agosto de 1999, entre Pakistán e India (2).

Al respecto Pezzano destaca, en criterio que compartimos, el particular énfasis que la Declaración de Manila otorga a las negociaciones, ya que los Estados deben

(2) Cfr. Arial Incident of 10 August 1999 (Pakistan v. India), Jurisdiction of the Court, Judgment, I.C.J. Reports 2000 (p. 32, párr. 45). 
tenerlas presentes como un medio flexible y eficaz de arreglo pacífico de sus controversias que, de ser utilizado, poseen una impronta efectiva para arribar a un pronto arreglo aceptable para las partes (Pezzano, 2016, p. 3).

De este modo, la Declaración de Manila completa el abanico de recursos a disposición de los Estados - en abierta promoción a la solución pacífica de controversias, aunque profundiza la "exclusividad" de los medios enunciados en la Carta de la ONU y no incluye a los buenos oficios- e insiste, complementariamente, en el arreglo basado a partir del principio de igualdad soberana y la libre elección de medios, sin perjuicio que aquellos procuren "de buena fe y con un espíritu de cooperación", el arreglo pronto y equitativo de sus controversias internacionales en las circunstancias y naturaleza de la controversia.

Por estas razones, la negociación aparece como la opción más importante de todos los métodos de solución pacífica de controversias, ya que la mayoría de las disputas quedan superadas gracias a este medio - en ocasiones, sin publicidad alguna- e incluso es utilizado como proceso en simultáneo a la aplicación de otros métodos, al punto de resultar a veces más apropiada. No obstante, no debe perderse de vista que el éxito de una negociación depende de factores como "(...) la aceptabilidad de las reclamaciones de cualquiera de las partes para con la otra, la moderación, el tacto y el espíritu de mutuo acuerdo con que lleven a cabo las negociaciones, y el estado de la opinión pública (...) respecto a las concesiones demandadas" (Sørensen, 1994, p. 632).

Finalmente, el resultado de las negociaciones reviste carácter satisfactorio para las partes que alcanzan - total o parcialmente - un acuerdo concreto, sin importar que aquello revista carácter transitorio, operativo o bien se trate de un procedimiento gradual que requiera de medidas internas adicionales para una completa ejecución posterior. En todos los casos, los progresos son valorados por la comunidad internacional. Lo anterior no significa restarle valor a aquellas negociaciones prolongadas o infructuosas, ya que aquellas controversias pueden ser sometidas luego a otros medios de solución para, posteriormente, encontrar finalmente su solución en un regreso de las negociaciones bajo nuevas circunstancias, tal como señalaremos en análisis casuísticos más adelante.

\section{El desafío de las negociaciones contemporáneas y su situación espacio-temporal. Del impasse diplomático a la solución concertada y sostenible}

Actualmente, las negociaciones se realizan de modo personal y presencial, último aspecto que suele ser reemplazado por video-conferencia, correo electrónico, comunicación por videollamada en plataformas móviles, sin perjuicio de la 
EL PROCESO NEGOCIADOR EN EL DERECHO INTERNACIONAL CONTEMPORÁNEO: DE LA ELABORACIÓN DE ACUERDOS A LA SOLUCIÓN DE CONTROVERSIAS INTERNACIONALES

- LEOPOLDO M. A. GODIO (PP. 495-526)

correspondencia diplomática oficial. En cualquiera de estos formatos, la negociación internacional comprende un contacto entre dos individuos legitimados para resolver cuestiones de interés común para sus administraciones. Aunque las negociaciones pueden abordar aspectos principales o secundarios en desacuerdo con meridiana precisión, se ha afirmado correctamente que no existen reglas exactas o exhaustivas al respecto de este procedimiento (Hakapää, 2012, párr. 29).

En ese sentido, los plazos en materia de negociaciones no parecen disponer de límites claros según el derecho internacional general, aunque convencionalmente se han incluido disposiciones en el artículo 16 (1) de la Convención sobre el Comercio de Tránsito de los Estados sin Litoral de 1965; el artículo 66 de la Convención de las Naciones Unidas contra la Corrupción de 2003; y el artículo 27 de la Convención de las Naciones Unidas sobre las inmunidades jurisdiccionales de los Estados y de sus bienes de 2004.

Lo anterior no significa que, en el derecho internacional general, exista una prevalencia entre los distintos medios de solución pacífica de controversias. Nuestra afirmación constituye un desprendimiento del artículo 33 de la Carta de las Naciones Unidas, que reconoce a la negociación como un procedimiento disponible sin obligación en cuanto a su implementación, ya que la única exigencia de la norma radica en la búsqueda de la solución mediante medios pacíficos. En idéntico sentido lo reafirmó la Asamblea General al recordar, en la Resolución 53/101 dedicada a los Principios y directrices para las negociaciones internacionales, que "(...) la existencia de diferentes medios para el arreglo pacífico de las controversias, según han sido consagrados en la Carta y reconocidos en el derecho internacional, y reafirmando en este contexto el derecho a elegir libremente esos medios".

Sin embargo, Hakapää advierte que las negociaciones suelen ofrecer una oportunidad de inicio para las partes y en cuyo otro extremo se encuentra la decisión judicial vinculante y sometida a un tercero ajeno a estas, razón por la cual no es sorprendente que procuren evitar el foro jurisdiccional, ya que muchas veces las consecuencias de un laudo o una sentencia exceden los aspectos legales e involucran consideraciones políticas o económicas (Hakapää, 2012, párrs. 25-26).

Por estas razones, resulta habitual que los acuerdos internacionales contengan disposiciones genéricas que inviten a resolver los diferendos mediante la negociación u otro medio político - aspecto que explica el frecuente recurso a la consulta y el intercambio de opiniones dentro de una negociación - sin restringirlo a etapas sujetas a preclusión o compartimentos estancos que caracterizan al derecho local. En efecto, la práctica internacional reconoce a la negociación como un requisito vinculante concreto, de carácter convencional, tales como el artículo 41 de la Convención de Viena sobre la Sucesión de Estados en Materia de Tratados de 1978; el artículo 283 de la Convención de las Naciones Unidas sobre el Derecho del 
Mar de 1982; o los artículos 3 (7), 4, 5 (2) y (5), y 11 del Entendimiento de Solución de Diferendos de la Organización Mundial de Comercio, entre otras.

En este último tema, el procedimiento de solución de controversias de la Convención de las Naciones Unidas sobre el Derecho del Mar de 1982 excluye facultativamente, ante la declaración de los Estados Parte en tal sentido, los foros y procedimientos disponibles en la Sección 2 de la Parte XV concernientes a aspectos puntuales de interpretación y determinación de delimitación marítima, o las relativas a bahías o títulos históricos, que pueden ser sometidos a conciliación obligatoria, luego de un periodo "razonable" de negociaciones. Para el resto de las excepciones facultativas - referidas a las actividades militares y los asuntos que se encuentren bajo análisis del Consejo de Seguridad de la ONU - las partes solo pueden recurrir a los procedimientos no adversariales de la Sección 1 de la Parte XV (Godio, 2019, pp. 435-469).

Precisamente, es útil destacar la exitosa utilización de conciliación y la negociación - los procedimientos no adversariales dispuestos en la Sección 1 de la Parte XV de la Convención de 1982- por parte de Timor Oriental, en una controversia "estancada unilateralmente" por Australia desde el año 2003, a través de una actitud inflexible (Rodríguez, 2019, p. 149). En el aspecto que nos interesa, Timor Oriental consideró que el artículo 298 de la Convención de 1982 se refiere a un transcurso del tiempo "razonable" y que ello no significaba que una de las partes deba esperar eternamente cuando no existen perspectivas reales de negociación(3).

En efecto, la afirmación de Timor Oriental no se trató de un aspecto menor, ya que el artículo 298 de la Convención de 1982 no puede resultar en una exigencia de modo que otorgue, a una de las partes, la posibilidad de vetar toda oportunidad de recurrir a la conciliación obligatoria a través de la mera negativa a negociar. Una vez que la comisión de conciliación se declaró competente(4), las partes mantuvieron una serie de reuniones confidenciales que alcanzaron, por primera vez, resultados sustanciales que fueron notificadas a la comisión para facilitar el proceso de conciliación y crear las condiciones propicias para obtener un acuerdo de límites marítimos permanentes en el Mar de Timor, el cual fue alcanzado luego de treces reuniones distribuidas en ocho meses de duración. El Tratado de Límites Marítimos, que comprende además acuerdos de distribución, exploración, explotación y administración de la zona antes en disputa, fue firmado el 6 de marzo de 2018.

(3) Cfr. Conciliation between The Democratic Republic of Timor-Leste and The Commonwealth of Australia, P.C.A., Decision on Compentence, 19 September 2016 (párr. 23-28).

(4) Cfr. Conciliation between The Democratic Republic of Timor-Leste and The Commonwealth of Australia, P.C.A., of the compulsory conciliation commission between Timor-Leste and Australia on the Timor Sea, 9 May 2018 (párr. 52). 
EL PROCESO NEGOCIADOR EN EL DERECHO INTERNACIONAL CONTEMPORÁNEO: DE LA ELABORACIÓN DE ACUERDOS A LA SOLUCIÓN DE CONTROVERSIAS INTERNACIONALES - LEOPOLDO M. A. GODIO (PP. 495-526)

En otro ejemplo, previo al anterior, es posible recordar la controversia sobre utilización de Aspersión Aérea de Herbicida (5). Las negociaciones entre los contendientes demostraron su idoneidad para resolver disputas internacionales. Aunque aquellas habían llegado a un "punto muerto" y motivaron el inicio de un proceso judicial de Ecuador contra Colombia ante la CIJ — presentada el 31 de marzo de 2008 - lo cierto es que su competencia y conocimiento no impidió a las partes a reanudar y proseguir, en paralelo, la negociación diplomática.

En apretada síntesis, luego de las dos rondas de presentación de escritos de las partes (Memoria-Contramemoria y Réplica-Dúplica) y pocos días antes iniciar el procedimiento oral, el agente de Ecuador notificó a la CIJ un acuerdo celebrado el 9 de septiembre de 2013, que puso fin a la controversia en su totalidad. En la comunicación del acuerdo, a pesar de encontrar la solución del diferendo en la negociación, ambas partes manifestaron su agradecimiento a la CIJ por su intervención y señalaron que el sometimiento una controversia ante el tribunal no debía ser considerado como un acto hostil(6).

Por último, es posible traer a colación una disputa internacional resuelta mediante la negociación y cuyo origen - así como su desenlace - sorprendió a más de un especialista: el caso relativo a la conservación y explotación sostenible de las Poblaciones de Pez Espada en el Océano Pacífico Sur, que involucró a la Unión Europea (UE) y la República de Chile, que presentó el potencial riesgo de dos decisiones contradictorias en procedimientos paralelos y simultáneos, iniciados ante la OMC y el Tribunal Internacional del Derecho del Mar, respectivamente.

En resumen, la controversia se concentró en la figura del pez espada - una especie transzonal y altamente migratoria perteneciente al océano Pacífico sudoriental- y el intento de la UE de reducir la presión pesquera en aguas comunitarias, a finales del siglo XX, debido a la sobreexplotación de los recursos ictícolas y la búsqueda de otros caladeros para su reemplazo (Godio, 2013, p. 1).

Durante la última década del siglo pasado, Chile tuvo una permanente disputa con la UE por la pesca en el Pacífico Sur y sancionó una norma que prohibió descargar pez espada en puertos chilenos a fin de desalentar la depredación del recurso, con fundamento en la Convención de las Naciones Unidas sobre el Derecho del Mar. Ello motivó que en abril de 2000 la UE activase el procedimiento de Entendimiento de Solución de Diferendos de la OMC y Chile presentase una

(5) Cfr. Aerial Herbicide Spraying (Ecuador v. Colombia), Order of 13 September 2013, I.C.J. Reports 2013 (p. 278).

(6) Aerial Herbicide Spraying (Ecuador v. Colombia), Order of 13 September 2013, I.C.J. Reports 2013 (pp. 278-279). 
demanda, en diciembre del mismo año, ante el Tribunal de Internacional del Derecho del Mar.

En 2001, la UE y Chile acordaron suspender provisoriamente el procedimiento y luego de sucesivas renovaciones - en 2003, 2005, 2007- anunciaron, en octubre de 2008, la obtención de acuerdo negociado sobre un proyecto de texto titulado "Entendimiento relativo a la conservación de las poblaciones de pez espada en el Océano Pacífico sudoriental" y solicitaron una nueva suspensión. Finalmente, las partes acordaron retirar definitivamente ambos casos a fines del año 2009 (7).

Este último caso sea, posiblemente, un excelente ejemplo de cómo los Estados pueden obtener, a través de la negociación, una solución que satisfaga los intereses de ambas partes y descartar, al mismo tiempo, el "juego de suma cero" que representaba el riesgo de dos procedimientos simultáneos y en tribunales creados con fines diferentes. Asimismo, el beneficio de esta negociación directa por fuera de los foros, trascendió la controversia, ya que se trató de unas de las condiciones de prueba piloto que luego culminó en un convenio de cooperación en el año 2001 (Orellana, 2001) y posteriormente, en un acuerdo de libre comercio entre la UE y Chile, firmado en 2002, gracias a una metodología política que se logró superar un diferendo mucho más profundo que la simple sobrepesca (Martínez, 2019, pp. 623-624).

\section{La negociación en la jurisprudencia de la Corte Internacional de Justicia}

Se trata de un aspecto interesante a considerar, ya que en algunas controversias y opiniones consultivas la CIJ — como también su predecesora - tuvo ocasión de examinar a las negociaciones de dos maneras distintas: 1) como propósito en sí mismo; y 2) como "requisito" previo para el agotamiento de esfuerzos antes de recurrir a la vía judicial.

\section{IV.1. La negociación como fin en sí misma}

En el primer grupo de asuntos, la Corte (8) consideró a la negociación autónomamente - es decir, por sí misma - en la controversia referida a la navegación en el caso del Gran Belt. Durante el desarrollo del asunto, el tribunal declaró que el

(7) Cfr. Conservation and Sustainable Exploitation of Swordfish Stocks (Chile/European Union), Order of 16 December 2009, ITLOS Reports 2008-2010 (p. 13).

(8) También fue considerada anteriormente por la CPJI, al señalarse que independientemente de las formas concretas de materialización, las negociaciones constituyen un intercambio de puntos de vista de hecho y de derecho, sumados a compromisos mutuos para alcanzar a una solución directa 
EL PROCESO NEGOCIADOR EN EL DERECHO INTERNACIONAL CONTEMPORÁNEO: DE LA ELABORACIÓN DE ACUERDOS A LA SOLUCIÓN DE CONTROVERSIAS INTERNACIONALES

- LEOPOLDO M. A. GODIO (PP. 495-526)

valor de cualquier negociación entre las partes, en espera de una decisión sobre el fondo y a fin de llegar a un arreglo directo y amigable, era bienvenido (9).

La negociación fue considerada, en igual sentido, en el caso relativo al personal diplomático y consular de los Estados Unidos en Teherán(10), al resolver que la forma y el monto de la indemnización - a cargo de Irán- iba a ser decidida por la Corte en caso que las partes no alcanzaran un acuerdo negociado al respecto, reservándose para ese fin los procedimientos subsiguientes(11).

Asimismo, la Corte consideró las consecuencias de las negociaciones en el asunto de delimitación marítima entre Qatar y Bahréin, al determinar su competencia a partir de una Minuta de reunión celebrada por las partes, la que poseía claros efectos jurídicos independientemente de su denominación particular, por aplicación de la Convención de Viena sobre el Derecho de los Tratados de 1969(12).

Finalmente, al tratar las excepciones preliminares rusas en la controversia sobre Aplicación de la Convención Internacional sobre la eliminación de todas las formas de discriminación racial, en 2011, la CIJ analizó el concepto mismo de "negociación" como algo más que un simple intercambio de opiniones jurídicas o intereses entre las partes, de modo que supera a las meras protestas, acusaciones y rechazos al punto que difiere de la "controversia", ya que exige el compromiso de una de las Partes a debatir con miras a resolver la disputa (13).

\section{IV.2. La negociación requisito previo al método judicial}

En esta segunda categoría, la CIJ analizó a la negociación como requisito de condición para el examen de su competencia. Aquí corresponde incluir la atención que merecieron de las excepciones preliminares de los Casos relativos al África Sudoriental, en el cual la Corte consideró que el requisito de habilitación

y amistosa. Cfr. Free Zones of Upper Savoy and the District of Gex, Order of 19 August 1929, P.C.I.J., Series A, No. 22 (p. 13).

(9) Cfr. Passage through the Great Belt (Finland v. Denmark), Provisional Measures, Order of 29 July 1991, I.C.J. Reports 1991 (p. 20, para. 35). Cabe destacar que las partes alcanzaron el acuerdo en cuestión y el caso fue retirado posteriormente del Registro de Casos de la CIJ en 1992. Cfr. Passage through the Great Belt (Finland v. Denmark), Order of 10 September 1992, I.C.J. Reports 1992 (p. 348).

(10) Cfr. United States Diplomatic and Consular Staff in Tehran, Judgment, I.C.J. Reports 1980 (p. 3).

(11) United States Diplomatic and Consular Staff in Tehran, Judgment, I.C.J. Reports 1980 (p. 45, párr. 95).

(12) Cfr. Maritime Delimitation and Territorial Questions between Qatar and Bahrain, Jurisdiction and Admissibility, Judgment, I.C.J., Reports 1994 (p. 120, párrs. 22-23).

(13) Cfr. Application of the International Convention on the Elimination of All Forms of Racial Discrimination (Georgia v. Russian Federation), Preliminary Objections, Judgment, I.C.J. Reports 2011 (pp. 130-131, párr. 150). 
de controversias - irresuelto mediante negociación- no podía entenderse como una imposibilidad de alcanzar un acuerdo, sino la ausencia de posibilidad razonable de futuras negociaciones que conduzcan a él. La Corte advirtió, en consecuencia, que lo importante no era la forma de las negociaciones, sino la actitud y el punto de vista de las partes sobre las cuestiones de fondo(14).

El último aspecto tuvo similar consideración por la CIJ en el reclamo ulterior sobre Actividades armadas en el territorio del Congo (15); así como también en el examen de la aplicación del artículo 22 de la Convención Internacional sobre la Eliminación de todas las Formas de Discriminación Racial(16) y respecto del artículo 29 (1) de la Convención sobre la eliminación de todas las formas de discriminación contra la Mujer, controversia en la cual el tribunal señaló que poseía competencia "respecto de la interpretación o aplicación del convenio" si ello no fue posible de solución por las partes a través de la negociación. Al respecto, la Corte consideró que el proceso negociador contiene condiciones acumulativas y que, en el caso concreto, no se había demostrado su realización —además de advertir la orfandad de propuestas concretas por parte de la República Democrática del Congo en tal sentido- y que, al no intentarse una negociación de la disputa con antelación al proceso judicial, carecía de competencia (17).

Idéntico examen realizó el tribunal en el caso de la Aplicación de la Convención internacional sobre la eliminación de todas las formas de discriminación racial, al advertir que la controversia y el inicio de negociaciones constituyen cuestiones diferentes, toda vez que las últimas pueden ayudar a demostrar la existencia de la disputa y delinear su materia. Sin embargo, es útil señalar que, para establecer su competencia, la CIJ debió determinar el "genuino" intento de una de las partes para discutir activamente con la contraparte el objeto de la disputa y su propósito de resolverla(18), ya que la condición de la negociación previa solo se cumple ante su fracaso, inutilidad o estancamiento (19).

(14) Cfr. South West Africa (Ethiopia v. South Africa; Liberia v. South Africa), Preliminary Objections, Judgment, I.C.J. Reports 1962 (p. 345 y ss.).

(15) Cfr. Armed Activities on the Territory of the Congo (New Application: 2002) (Democratic Republic of the Congo v. Rwanda), Jurisdiction and Admissibility, Judgment, I.C.J. Reports 2006 (p. 6).

(16) Armed Activities on the Territory of the Congo (New Application: 2002) (Democratic Republic of the Congo v. Rwanda), Jurisdiction and Admissibility, Judgment, I.C.J. Reports 2006 (pp. 33-35, párrs. 71-79).

(17) Armed Activities on the Territory of the Congo (New Application: 2002) (Democratic Republic of the Congo v. Rwanda), Jurisdiction and Admissibility, Judgment, I.C.J. Reports 2006 (pp. 35-43, párrs. 80-101).

(18) Cfr. Application of the International Convention on the Elimination of All Forms of Racial Discrimination (Georgia v. Russian Federation), Preliminary Objections, Judgment, I.C.J. Reports 2011 (p. 132, párr. 157).

(19) Application of the International Convention on the Elimination of All Forms of Racial Discrimination (Georgia v. Russian Federation), Preliminary Objections, Judgment, I.C.J. Reports 2011 (p. 133, párr. 159).

Revista Anales de la Facultad de Ciencias Jurídicas y Sociales. Universidad Nacional de La Plata. UNLP.

Año 18/№ 51-2021. Anual. Impresa ISSN 0075-7411-Electrónica ISSN 2591-6386 
EL PROCESO NEGOCIADOR EN EL DERECHO INTERNACIONAL CONTEMPORÁNEO: DE LA ELABORACIÓN DE ACUERDOS A LA SOLUCIÓN DE CONTROVERSIAS INTERNACIONALES

- LEOPOLDO M. A. GODIO (PP. 495-526)

De manera similar, la Corte evaluó su competencia para entender en la controversia sobre las Cuestiones referentes a la obligación de juzgar o extraditar, en la cual examinó las condiciones de habilitación requeridas en la Convención contra la tortura y otros tratos o penas crueles, inhumanas o degradantes(20). Resulta interesante señalar que las partes habían celebrado reuniones e intercambios de correspondencia - entre enero y junio de 2006, calificadas por Bélgica como "negociaciones" y que ello no fue desconocido por Senegal-, razón por la cual la CIJ observó que se trataba de divergencias de opiniones entre las partes, que persistieron en la etapa oral del proceso, y demostró que la controversia no pudo resolverse mediante negociaciones $(21)$.

En la misma línea de razonamiento, la CIJ declaró favorable su competencia en el asunto de Delimitación Marítima en el Mar Negro, atento al cumplimiento de una disposición convencional entre las partes que autorizaba su sometimiento al tribunal luego de fracasar las negociaciones, y dentro de un periodo razonable que no superase los dos años (22).

El resultado infructuoso de las negociaciones también fue objeto de análisis por la Corte en el Caso de las plantas de celulosa sobre el río Uruguay, en el cual examinó la labor del Grupo Técnico de Alto Nivel —en relación con la Comisión de Administración del Río Uruguay- y su carácter de foro negociador entre las partes (23), para luego concluir que Uruguay carecía de derecho para autorizar la construcción de las plantas y la terminal portuaria, en clara violación del Estatuto del Río Uruguay de 1975(24), toda vez que la omisión del mecanismo de cooperación y consulta allí dispuesto equivaldría a que las negociaciones entre las partes carecieran de sentido (25). Asimismo, la Corte consideró que el artículo 12 del mismo Estatuto no establece una obligación de recurrir a la propia CIJ, sino la posibilidad de realizarlo al concluir el periodo de negociación(26) y que Uruguay

(20) Cfr. Questions relating to the Obligation to Prosecute or Extradite (Belgium v. Senegal), Judgment, I.C.J. Reports 2012 (p. 445, párr. 56).

(21) Questions relating to the Obligation to Prosecute or Extradite (Belgium v. Senegal), Judgment, I.C.J. Reports 2012 (p. 446, párr. 58-59).

(22) Cfr. Maritime Delimitation in the Black Sea (Romania v. Ukraine), Judgment, I.C.J. Reports 2009 (p. 71 y 74, párrs. 21 y 28).

(23) Cfr. Pulp Mills on the River Uruguay (Argentina v. Uruguay), Judgment, I.C.J. Reports 2010 (p. 65, párr. 139).

(24) Pulp Mills on the River Uruguay (Argentina v. Uruguay), Judgment, I.C.J. Reports 2010 (pp. 66-67, párr. 143).

(25) Pulp Mills on the River Uruguay (Argentina v. Uruguay), Judgment, I.C.J. Reports 2010 (p. 67, párr. 147).

(26) Pulp Mills on the River Uruguay (Argentina v. Uruguay), Judgment, I.C.J. Reports 2010 (pp. 69-70, párr. 155).

Revista Anales de la Facultad de Ciencias Jurídicas y Sociales. Universidad Nacional de La Plata. UNLP. Año 18/№ 51-2021. Anual. Impresa ISSN 0075-7411-Electrónica ISSN 2591-6386 
había incumplido aquel al iniciar unilateralmente las obras y violó las obligaciones procedimentales establecidas en el acuerdo (27).

Finalmente, en cuanto la prueba de existencia de la negociación, la Corte señaló que la demostración del "intento" no exige arribar a un acuerdo, aunque aclaró que, ante la ausencia de evidencias de un auténtico intento, era posible concluir que no se había cumplido con el requisito de negociación previa (28).

\section{La "obligación de negociar" en la Corte Permanente de Justicia Internacional y la Corte Internacional de Justicia}

Según la CPJI, el compromiso de asumir una negociación incluye la obligación de asegurar la buena comprensión de las naciones y afirmó, en su opinión consultiva sobre el Tráfico ferroviario entre Lituania y Polonia, que las negociaciones no solo debían iniciarse, sino también proseguir tanto como fuese posible a fin de alcanzar un acuerdo. Sin embargo, advirtió que la "obligación de negociar" no incluye el éxito del resultado(29).

$\mathrm{Al}$ respecto, es necesario señalar que la importancia de la obligación, en este asunto, tiene fundamento en la "aceptación" y participación de Lituania y Polonia, a invitación del Consejo de la Sociedad de las Naciones, en la adopción de la recomendación de 1927 e iniciar, posteriormente, las negociaciones entre ellas desde 1928. En otras palabras, se trata de la participación activa en la conformación de la expresión de voluntad de un órgano, que originó la obligación de iniciar y posteriormente continuar las negociaciones en función de alcanzar un acuerdo.

Por otra parte, en el caso de la Plataforma Continental del Mar del Norte la CIJ consideró que las partes estaban obligadas a establecer negociaciones significativas para alcanzar un acuerdo - en el sentido de no insistir en la propia posición sin contemplar cualquier modificación- y no como un mero formalismo procesal(30). Merece incluirse en este punto las reflexiones de Pastor Ridruejo, para quien la obligación de una negociación impuesta como norma de derecho internacional equivale a que las partes de una controversia carezcan de libertad en el comportamiento, cosa que no ocurre si una de las partes insiste tenazmente su posición sin intención de modificarla, lo que exige la aplicación del principio de buena fe (Pastor Ridruejo, 2011, p. 595).

(27) Pulp Mills on the River Uruguay (Argentina v. Uruguay), Judgment, I.C.J. Reports 2010 (p. 104, párr. 275).

(28) Cfr. Application of the International Convention on the Elimination of All Forms of Racial Discrimination (Georgia v. Russian Federation), Preliminary Objections, Judgment, I.C.J. Reports 2011 (p. 133, párr. 159).

(29) Cfr. Railway Traffic between Lithuania and Poland, Advisory Opinion, 1931, P.C.I.J., Series A/B, No. 42 (pp. 115-116).

(30) Cfr. North Sea Continental Shelf, Judgment, I.C.J. Reports 1969 (pp. 46-47, párr. 85). 
EL PROCESO NEGOCIADOR EN EL DERECHO INTERNACIONAL CONTEMPORÁNEO: DE LA ELABORACIÓN DE ACUERDOS A LA SOLUCIÓN DE CONTROVERSIAS INTERNACIONALES

- LEOPOLDO M. A. GODIO (PP. 495-526)

$\mathrm{Al}$ respecto, la Corte también tuvo oportunidad de opinar sobre la obligatoriedad de negociar en ocasión de considerar el asunto de la Legalidad de la amenaza o el empleo de armas nucleares y afirmó que en el artículo VI del Tratado sobre la no Proliferación de las Armas Nucleares (1968) existía una obligación de llevar a cabo negociaciones de buena fe y concluirlas de modo que conduzca al desarme nuclear en todos sus aspectos bajo un control internacional estricto y efectivo (31). Al respecto, Bedjaoui - presidente de la Corte en el dictamen - opinó que era posible ir más allá de las conclusiones del tribunal y señaló la existencia de una doble obligación general, oponible erga omnes, de negociar de buena fe y alcanzar un resultado determinado (32).

Posteriormente, en el asunto sobre Jurisdicción en materia de Pesquerías la Corte consideró que la negociación era el método más apropiado para la solución de la controversia, considerando equilibradamente los derechos e intereses de las partes. Asimismo, advirtió que las negociaciones a realizarse con posterioridad a su decisión debían realizarse sobre la base de la buena fe(33).

El derecho del mar contribuyó, una vez más, al debate sobre la negociación en oportunidad de una controversia sobre límites marítimos entre Estados con costas opuestas o adyacentes en el Golfo de Maine. Allí la Corte consideró que era necesario alcanzar un acuerdo observando la buena fe y la genuina intención de alcanzar un resultado positivo entre las partes (34).

En tiempos más recientes, entre 2014 y 2016, la CIJ analizó las solicitudes de las Islas Marshall contra el Reino Unido(35), la India (36) y Pakistán(37) en las controversias sobre Obligaciones respecto de las negociaciones sobre la cesación de la carrera de

(31) Cfr. Legality of the Threat or Use of Nuclear Weapons, Advisory Opinion, I.C.J. Reports 1996 (pp. 263-265 y 267, párrs. 98-103 y $105 \mathrm{~F}$ ).

(32) Legality of the Threat or Use of Nuclear Weapons, Advisory Opinion, I.C.J. Reports 1996 (pp. 273-274, párr. 23).

(33) Cfr. Fisheries Jurisdiction (United Kingdom v. Iceland), Merits, Judgment, I.C.J. Reports 1974 (pp. 33-34, párr. 78).

(34) Cfr. Delimitation of the Maritime Boundary in the Gulf of Maine Area, Judgment, I.C.J. Reports 1984 (pp. 299-300, párr. 112 [1]).

(35) Cfr. Obligations concerning Negotiations relating to Cessation of the Nuclear Arms Race and to Nuclear Disarmament (Marshall Islands v. United Kingdom), Preliminary Objections, Judgment, I.C.J. Reports 2016 (p. 833).

(36) Cfr. Obligations concerning Negotiations relating to Cessation of the Nuclear Arms Race and to Nuclear Disarmament (Marshall Islands v. India), Jurisdiction and Admissibility, Judgment, I.C.J. Reports 2016 (p. 255).

(37) Cfr. Obligations concerning Negotiations relating to Cessation of the Nuclear Arms Race and to Nuclear Disarmament (Marshall Islands v. Pakistan), Jurisdiction and Admissibility, Judgment, I.C.J. Reports 2016 (p. 552). 
armamentos nucleares y el desarme nuclear(38). En la demanda contra el Reino Unido, el reclamante alegó el incumplimiento del derecho consuetudinario y la violación del artículo VI del Tratado de No Proliferación de Armas Nucleares (TNP). Asimismo, solicitó al tribunal la adopción de todas las medidas necesarias para obtener su cumplimiento, así como la realización de negociaciones de buena fe -iniciándolas de ser necesario- para concluir con un acuerdo que resulte en un estricto y eficaz desarme nuclear. En junio de 2015 el Reino Unido opuso excepciones preliminares, las que se resolvieron en su favor al año siguiente, por inexistencia de una controversia (39).

Respecto de la India y Pakistán —en procesos separados-, aunque ambos Estados no habían ratificado el TNP, las Islas Marshall alegaron que aquel acuerdo no establecía conductas simplemente mediante convenciones y que aquellas revestían carácter consuetudinario, en particular el artículo VI, razón por la ambos Estados demandados habían infringido un deber jurídico de cumplir, de buena fe, aquella obligación internacional. Finalmente, la CIJ también admitió las excepciones preliminares de India y Pakistán, rechazando la admisibilidad del caso, por nueve votos contra siete (40).

\section{La interpretación de Corte Internacional de Justicia respecto de la obligación de negociar el acceso al océano Pacífico}

Aunque la decisión de la CIJ en el asunto Obligación de negociar el acceso al océano Pacífico (41) no constituye más que una "Ley para las Partes" - Bolivia y Chile-, merece algunos comentarios y aclaraciones respecto de la negociación como proceso y solución de disputas internacionales.

Preliminarmente, corresponde advertir que la controversia no consistió en obtener una "salida al mar", sino en determinar la existencia de una obligación negociar de buena fe - que, según Bolivia, Chile habría asumido-, actitud que constituye uno de los pilares de las relaciones pacíficas entre los Estados y que se trata

(38) También presentó solicitudes contra China, EEUU, Francia, Rusia, Israel y la República Popular Democrática de Corea, pero aquellas no prosperaron por ausencia de competencia de la CIJ.

(39) Cfr. Obligations concerning Negotiations relating to Cessation of the Nuclear Arms Race and to Nuclear Disarmament (Marshall Islands v. United Kingdom), Preliminary Objections, Judgment, I.C.J. Reports 2016 (pp. 586-587, párr. 59).

(40) Cfr. Obligations concerning Negotiations relating to Cessation of the Nuclear Arms Race and to Nuclear Disarmament (Marshall Islands v. India), Jurisdiction and Admissibility, Judgment, I.C.J. Reports 2016, p. 277, para. 56. Cfr. Obligations concerning Negotiations relating to Cessation of the Nuclear Arms Race and to Nuclear Disarmament (Marshall Islands v. Pakistan), Jurisdiction and Admissibility, Judgment, I.C.J. Reports 2016 (p. 573, párr. 56).

(41) Cfr. Obligation to Negotiate Access to the Pacific Ocean (Bolivia v. Chile), Judgment, I.C.J. Reports 2018 (p. 507). 
EL PROCESO NEGOCIADOR EN EL DERECHO INTERNACIONAL CONTEMPORÁNEO: DE LA ELABORACIÓN DE ACUERDOS A LA SOLUCIÓN DE CONTROVERSIAS INTERNACIONALES

de un principio general de derecho, reconocido en la Carta de la ONU y distintos acuerdos internacionales de carácter bilateral, regional y general.

A continuación, presentaremos una breve referencia de los principales aspectos del caso, siguiendo una estructura que comprende: las posiciones de las partes y el derecho invocado por estas; la naturaleza de la obligación de negociar y su alcance en las consideraciones de la Corte, para luego referirnos a la propia decisión del tribunal.

\section{VI.1. Síntesis de los hechos, posiciones de las partes y derecho invocado}

El 24 de abril de 2013, Bolivia interpuso una demanda contra Chile respecto a la obligación de negociar "de buena fe y de forma efectiva" para alcanzar un acuerdo que le otorgue un acceso "pleno y soberano" al océano Pacífico (42).

La solicitud de Bolivia - que contiene un resumen de los hechos históricos, según la visión de aquel Estado, desde su independencia en 1825(43) - se orientó a demostrar los principales acontecimientos pertinentes que fundan su reclamo, enumerados en: 1) la existencia de la obligación de negociar; 2) el incumplimiento de esa obligación por parte de Chile; y, 3) el deber de Chile de cumplir esa obligación(44).

La afirmación de la tesis boliviana era la existencia de obligaciones generales en la materia, creadas en virtud del derecho internacional y en actos particulares vinculantes para Chile a través de convenios, acuerdos, práctica diplomática y una serie de declaraciones - algunos con carácter de actos unilaterales- atribuibles a sus representantes de más alto nivel, dedicados a negociar un "acceso soberano de Bolivia océano Pacífico". En consecuencia, Bolivia solicitó a la Corte que falle y declare que Chile: 1) tiene la obligación de negociar con Bolivia a fin de llegar a un acuerdo que otorgue a Bolivia acceso pleno y soberano al océano Pacífico; 2) ha incumplido dicha obligación; y, 3) debe cumplir dicha obligación de buena fe, pronta y formalmente, en un plazo razonable y de manera efectiva, a fin de otorgar a Bolivia acceso pleno y soberano al océano Pacífico (45).

(42) Obligation to Negotiate Access to the Pacific Ocean (Bolivia v. Chile), Judgment, I.C.J. Reports 2018 (p. 515, párr. 1).

(43) Obligation to Negotiate Access to the Pacific Ocean (Bolivia v. Chile), Judgment, I.C.J. Reports 2018 (pp. 518-538, párr. 16-83).

(44) Obligation to Negotiate Access to the Pacific Ocean (Bolivia v. Chile), Judgment, I.C.J. Reports 2018 (pp. 516-517, párr. 13).

(45) Obligation to Negotiate Access to the Pacific Ocean (Bolivia v. Chile), Judgment, I.C.J. Reports 2018 (p. 517, párr. 14). 
El fundamento de la competencia de la Corte fue el artículo XXXI del Tratado Americano de Soluciones Pacíficas del 30 de abril de 1948 -más conocido como Pacto de Bogotá-, del que ambos Estados son Parte. La Corte aceptó su competencia para conocer la controversia el 24 de septiembre 2015 y desestimó, en consecuencia, las excepciones preliminares opuestas por Chile (46).

Por su parte, la posición chilena negó la existencia de una obligación de negociar y argumentó que Bolivia buscó convertir los "intercambios diplomáticos históricos" y las "discusiones políticas" en acuerdos jurídicamente vinculantes siendo que - al momento de esos intercambios- ninguno de los dos Estados tenía intención alguna de crear una obligación jurídica.

Asimismo, Chile consideró que la carga probatoria - respecto a la existencia de una obligación de negociar - recaía sobre Bolivia y que no había podido demostrarse, así como tampoco había podido explicar: 1) el momento en el cual se considera que surgió la obligación; 2) el contenido de la obligación, incluido el significado de "acceso soberano"; 3) la duración de esa obligación y, en particular su persistencia actual; 4) que Chile estaba incumpliendo esa obligación; o 5) cómo Bolivia tenía derecho a una acción por ese alegado incumplimiento. Por estas razones, Chile concluyó que la petición boliviana debía ser desestimada por completo.

\section{VI.2. Los fundamentos alegados respecto de una obligación de negociar el acceso soberano de Bolivia al océano Pacífico}

Como adelantamos, Bolivia intentó demostrar la existencia de una obligación de negociar de buena fe el pronto, formal y efectivo acceso pleno al océano Pacífico. Al analizar los argumentos y la prueba aportada por aquel Estado respecto de los acuerdos bilaterales con Chile, la Corte recordó la importancia de este ítem en el reclamo, aspecto que debía ser demostrado en los distintos instrumentos y evidencias en los que se basaría aquella obligación, en particular: 1) el "Acta Protocolizada" de 1920, referida a una reunión celebrada entre el Ministro de Relaciones Exteriores de Bolivia y su par de Chile, así como los intercambios posteriores a esta, notas y memorandos de 1950 y 1961 (47); 2) una Declaración Conjunta firmada por los Jefes de Estado en Charaña, el 8 de febrero de 1975(48); 3) comuni-

(46) Cfr. Obligation to Negotiate Access to the Pacific Ocean (Bolivia v. Chile), Preliminary Objection, Judgment, I.C.J. Reports 2015 (pp. 610-611, párr. 56).

(47) Obligation to Negotiate Access to the Pacific Ocean (Bolivia v. Chile), Judgment, I.C.J. Reports 2018 (pp. 519-530, párrs. 26-59).

(48) Obligation to Negotiate Access to the Pacific Ocean (Bolivia v. Chile), Judgment, I.C.J. Reports 2018 (pp. 530-534, párrs. 60-70). 
EL PROCESO NEGOCIADOR EN EL DERECHO INTERNACIONAL CONTEMPORÁNEO: DE LA ELABORACIÓN DE ACUERDOS A LA SOLUCIÓN DE CONTROVERSIAS INTERNACIONALES

- LEOPOLDO M. A. GODIO (PP. 495-526)

cados emitidos por los Ministros de Relaciones Exteriores de ambos Estados en noviembre de 1986 y la posterior Declaración Conjunta emitida el 22 de febrero de 2000 denominada "Declaración del Algarve" (49) y 4) un documento conocido como "Agenda de 13 puntos" elaborado durante la reunión de un grupo de trabajo bilateral, en 2006 (50), entre otros.

$\mathrm{Al}$ respecto, la Corte concluyó que ninguno de los instrumentos invocados por Bolivia constituía una obligación para Chile - en el sentido de negociar el acceso soberano de Bolivia al Océano Pacífico(51) - y que tanto el "Acta Protocolizada" como el intercambio de notas de 1950 tampoco podrían ser considerados acuerdos internacionales, al tiempo que el Memorándum de 1961 no creaba ni reafirmaba una obligación al respecto (52). En cuanto a la Declaración Conjunta de Charaña, el tribunal advirtió que tampoco revestía una confirmación de la obligación de negociar(53), aspecto que tampoco surge de la redacción de los comunicados de 1986(54), ni de la "Declaración del Algarve" de 2000 (55). Finalmente, la Corte examinó la denominada "Agenda de 13 puntos" del año 2006 y advirtió que aquella presentaba un título susceptible de análisis; aunque luego consideró que se trataba de un tema demasiado amplio para tratar el "acceso soberano de Bolivia al mar" y que su mera mención establece una obligación para las Partes a negociar ese contenido (56).

En relación con las declaraciones y otros actos unilaterales de Chile -que según Bolivia constituyen una generación respecto de su obligación de negociar-la Corte señaló que aquellas no podían ser consideradas en el sentido de adquirir

(49) Obligation to Negotiate Access to the Pacific Ocean (Bolivia v. Chile), Judgment, I.C.J. Reports 2018 (pp. 536-538, párrs. 76-83).

(50) Obligation to Negotiate Access to the Pacific Ocean (Bolivia v. Chile), Judgment, I.C.J. Reports 2018 (p. 551, párrs. 136-137).

(51) Obligation to Negotiate Access to the Pacific Ocean (Bolivia v. Chile), Judgment, I.C.J. Reports 2018 (p. 536, párr. 174).

(52) Obligation to Negotiate Access to the Pacific Ocean (Bolivia v. Chile), Judgment, I.C.J. Reports 2018 (p. 546, párrs. 117-119).

(53) Obligation to Negotiate Access to the Pacific Ocean (Bolivia v. Chile), Judgment, I.C.J. Reports 2018 (p. 548, párrs. 126-127).

(54) Obligation to Negotiate Access to the Pacific Ocean (Bolivia v. Chile), Judgment, I.C.J. Reports 2018 (pp. 549-550, párrs. 131-132).

(55) Obligation to Negotiate Access to the Pacific Ocean (Bolivia v. Chile), Judgment, I.C.J. Reports 2018 (p. 550, párr. 135).

(56) Obligation to Negotiate Access to the Pacific Ocean (Bolivia v. Chile), Judgment, I.C.J. Reports 2018 (p. 552, párr. 138). 
una obligación jurídica de negociar, sino en la voluntad de efectuar negociaciones y, en consecuencia, rechazó el argumento de Bolivia al respecto(57).

Respecto de la aquiescencia alegada por Bolivia - entendida como un reconocimiento tácito a partir de una conducta unilateral que la otra parte puede interpretar como consentimiento- la Corte examinó la eventual aceptación de Chile a negociar el acceso soberano al mar, pero rechazó aquella tesis, ya que el demandante no pudo identificar ninguna declaración que requiriese una respuesta o reacción por parte del demandado, razón por la cual no existía fundamento para obligar a Chile a negociar con base en esta (58).

En cuanto a la existencia del estoppel —una declaración o representación de aquella, realizada por una parte a otra, que provoque en la última un obrar en consecuencia bajo el convencimiento de la naturaleza del accionar inicial- el tribunal encontró que no se encontraban cumplidas las condiciones para su reconocimiento, a pesar de las repeticiones de manifestaciones chilenas al respecto, ya que aquellas no apuntaban a una “obligación de negociar". Por esta razón, el instituto del estoppel tampoco no pudo proporcionar la base legal para obligar a negociar la salida al mar(59).

Por otra parte, Bolivia afirmó que las negativas de Chile a establecer nuevas negociaciones frustraban sus expectativas legítimas. Sobre este reclamo, la Corte señaló que las referencias a aquellas era posible encontrarlas en disputas relacionadas a los acuerdos protección de inversiones - que contienen el derecho de proporcionar un trato justo y equitativo- pero que las expectativas legítimas no revisten carácter de principio de derecho internacional general que establezca, en definitiva, entidad legal para su reconocimiento (60).

Párrafo aparte merece la tesis boliviana tendiente a dotar de obligatoriedad a las once Resoluciones de la Asamblea General de las Organización de los Estados Americanos, dedicadas a la situación del acceso soberano de Bolivia al océano Pacífico. La Corte recordó el carácter no vinculante de aquellas y agregó que ninguna indica, en el caso, una obligación de negociar al respecto y que se limitan a recomendar, simplemente, que Bolivia y Chile realicen negociaciones. La CIJ advirtió

(57) Obligation to Negotiate Access to the Pacific Ocean (Bolivia v. Chile), Judgment, I.C.J. Reports 2018 (pp. 554-555, párrs. 146-148).

(58) Obligation to Negotiate Access to the Pacific Ocean (Bolivia v. Chile), Judgment, I.C.J. Reports 2018 (pp. 556-557, párr. 152).

(59) Obligation to Negotiate Access to the Pacific Ocean (Bolivia v. Chile), Judgment, I.C.J. Reports 2018 (pp. 558-559, párrs. 158-159).

(60) Obligation to Negotiate Access to the Pacific Ocean (Bolivia v. Chile), Judgment, I.C.J. Reports 2018 (p. 559, párr. 162). 
que la participación consensuada en la adopción de algunas resoluciones del organismo, no significaba entender a aquellas como vinculantes de conformidad con el derecho internacional, al tiempo que ni siquiera permite inferir la posición de Chile al respecto.

Finalmente, la Corte examinó la pretensión boliviana de aplicar el artículo 2 (3) de la Carta de la Organización de las Naciones Unidas y el artículo 3 de la Carta de la Organización de los Estados Americanos, tendiente a determinar la existencia de una "obligación de negociar" basada en aquellas disposiciones. El tribunal advirtió que aquellas normas establecen un deber genérico de resolver las controversias de modo pacífico, pero que no instituye ningún método específico, razón por la cual no es posible concluir que Chile poseía una obligación a negociar el acceso soberano al mar, con fundamento en aquellas(61).

\section{VI.3. La decisión de la Corte Internacional de Justicia}

Luego del análisis de los argumentos presentados por Bolivia, la Corte, previo a dictar sentencia, dedicó un lugar específico a la novedosa teoría boliviana de la "acumulabilidad" que, según la cual, en caso de que no existir un instrumento, acto o conducta que - analizada individualmente - genere la obligación de negociar, la suma de todos estos elementos y su efecto "acumulativo" resulta de naturaleza tal que genera un "efecto decisivo" para el nacimiento de tal obligación.

En respuesta a esta tesis, Chile afirmó que una acumulación de hechos sin obligaciones legales no puede crear tal necesidad por "acreción", es decir, por una suma de actos fragmentados y discontinuos en conjunto (62).

La Corte consideró que el argumento de Bolivia se basaba en una supuesta obligación originada en una acumulación de actos. Sin embargo, la CIJ advirtió que las pruebas y argumentos presentados por Bolivia no demostraron, individualmente, la existencia de una obligación jurídica de Chile y que la repetición de aquellos actos - no vinculantes - no puede alterar el resultado general ni crear una obligación(63).

(61) Obligation to Negotiate Access to the Pacific Ocean (Bolivia v. Chile), Judgment, I.C.J. Reports 2018 (pp. 560-561, párrs. 163-167).

(62) Obligation to Negotiate Access to the Pacific Ocean (Bolivia v. Chile), Judgment, I.C.J. Reports 2018 (p. 563, párr. 173).

(63) Obligation to Negotiate Access to the Pacific Ocean (Bolivia v. Chile), Judgment, I.C.J. Reports 2018 (p. 563, párr. 174). 
Si bien Bolivia y Chile tienen una larga historia de diálogos, intercambios y negociaciones con el objetivo de identificar una solución adecuada para el acceso al mar por parte de Bolivia, la Corte no pudo concluir - por 12 votos contra 3- sobre la base de las pruebas y argumentos, que Chile se encontraba obligado a negociar un acuerdo que le otorgue a Bolivia un acceso soberano al océano Pacífico. En consecuencia, la Corte rechazó las otras solicitudes de Bolivia basadas en la existencia de tal obligación(64).

Sin embargo, la Corte en su último párrafo, y de conformidad con el deber de solucionar las controversias por medios pacíficos, expresa con claridad meridiana que no debe entenderse a su sentencia como una negación u obstáculo para el diálogo entre las Partes, primando el espíritu de buena vecindad para abordar la controversia y sobre cuya solución ambos Estados reconocen como cuestión de interés mutuo (65).

\section{Consideraciones sobre la buena fe aplicada a la negociación como solución de controversias}

Aunque las disposiciones de la Carta de la Organización de las Naciones Unidas, a partir de los artículos 2 (3) y 33, así como de las resoluciones de los órganos competentes de las Naciones Unidas (66) que desarrollan sus principios, no reconocen la existencia de una obligación general de negociar en el derecho internacional - ya que la única exigencia se encuentra en la utilización de los medios pacíficos- parece que aquellas reclaman que, una vez comenzadas las negociaciones, las partes se encuentran obligadas a proceder "de buena fe".

En otras palabras, la buena fe trata de un principio que puede situarse "dentro" de un proceso negociador y que - según el caso en cuestión- puede adquirir potencialmente un carácter obligatorio si la negociación presenta en sí misma un carácter imperativo, como consecuencia de aplicar alguna fuente del derecho internacional con entidad o contenido suficiente para ello.

En primer lugar, el principio de la buena fe en negociaciones que no resultan obligatorias - tal como en el caso de Bolivia y Chile previamente analizado- nos

(64) Obligation to Negotiate Access to the Pacific Ocean (Bolivia v. Chile), Judgment, I.C.J. Reports 2018 (pp. 563-564, párr. 175).

(65) Obligation to Negotiate Access to the Pacific Ocean (Bolivia v. Chile), Judgment, I.C.J. Reports 2018 (p. 564, párr. 176).

(66) Tales como la Carta de la Organización de las Naciones Unidas; la Resolución AG 1514 (XV) de 1960; la Resolución AG 2065 (XX), de 1965; la Resolución AG 3160 (XXVIII), de 1973; la Resolución AG 31/49, de 1976; la Resolución AG 37/9, de 1982; la Resolución 40/21, de 1985 y reiteradas en las resoluciones $40 / 41,42 / 19$ y $43 / 25$, entre otras. 
EL PROCESO NEGOCIADOR EN EL DERECHO INTERNACIONAL CONTEMPORÁNEO: DE LA ELABORACIÓN DE ACUERDOS A LA SOLUCIÓN DE CONTROVERSIAS INTERNACIONALES

invita a preguntarnos si es posible admitir una negociación "sin buena fe" - es decir, de "mala fe" - como una conducta acorde al artículo 2 (3) de la Carta de las Naciones Unidas.

En otras palabras ¿Cuándo y cómo es exigible la buena fe durante las negociaciones? ¿Qué ocurre con los Estados que realizan posiciones inflexibles o implementan estrategias tendientes a modificar periódicamente sus puntos de negociación, con el objeto de evitar sistemáticamente la solución de la controversia?

La buena fe constituye un límite a la discrecionalidad estatal y resulta aplicable tanto respecto del cumplimiento de sus obligaciones, como también en el ejercicio de los derechos, a fin de no tolerar abusos al respecto. Este principio fue, asimismo, declarado por la Resolución 2625 (XXV) de la Asamblea General como uno de los pilares del ordenamiento internacional contemporáneo al reconocer que "todo Estado tiene el deber de cumplir de buena fe las obligaciones contraídas en virtud de los principios y normas de derecho internacional generalmente reconocidos" (Diez de Velasco Vallejo, 2013, pp. 151-153).

En lo referido estrictamente a las negociaciones, la Asamblea General ha incluido a la buena fe entre los Principios y directrices para las negociaciones internacionales, en aplicación de obligaciones contraídas en virtud del derecho internacional; así como al observar el deber de cooperación a fin de mantener la paz y la seguridad internacionales, promover la estabilidad y el progreso de la economía mundial, el bienestar general de las naciones y la cooperación internacional libre de toda discriminación basada en esas diferencias.

En adición, la misma Resolución confirmó la importancia de realizar estas negociaciones de acuerdo con el derecho internacional y de modo que facilite lo declarado por los Estados. En ese sentido, propone a aquellos ajustarse a una serie de directrices: 1) las negociaciones de buena fe; 2) tener debidamente en cuenta la participación apropiada de los Estados cuyos intereses vitales resulten afectados en los asuntos negociados; 3) observar que el propósito y el objeto de la negociación sean compatibles con los principios y normas del derecho internacional, incluyendo las disposiciones de la Carta; 4) que se atengan al marco mutuamente convenido para la realización de negociaciones; 5) procuren mantener un ambiente constructivo y abstenerse de cualquier comportamiento que pudiese dificultarlas e impedir su avance; 6) facilitar la realización o conclusión de las negociaciones, manteniendo la atención en sus objetivos principales; 7) avanzar hacia una solución justa y mutuamente aceptable.

En este criterio se enrola Barboza, para quien la buena fe es el pilar de conducta para toda negociación, constituyéndose especialmente como una obligación sui generis cuyo cumplimiento determina la actitud de las partes. En otras 
palabras, existe “(...) obligación de tratar de llegar a un acuerdo de buena fe, una obligación de sentarse a la mesa del arreglo pacífico, pero no de alcanzar dicho acuerdo, como es lógico, dada la naturaleza de las cosas, porque no se trata de una obligación individual" (Barboza, 2008, p. 290). En la misma línea, Tanzi señala que las partes tienen la obligación de buscar "genuinamente" —en nuestra opinión, entendemos, de "buena fe" - la solución pacífica de la disputa y que el fracaso en su intento exige continuar trabajando, a fin de evitar un agravamiento de la controversia (Tanzi, 2017, pp. 144-145).

Por otra parte, aunque su análisis se refiere a las disputas territoriales, Kohen señala que la buena fe es un principio fundamental del derecho internacional de todas las épocas, presente en la conclusión, la interpretación y aplicación de los tratados, pero también destaca su rol como guía de los actos en los Estados parte de un diferendo, ya que la buena fe permite conocer si aquellas podrían aceptar - eventualmente- las tesis o posiciones jurídicas de la contraria y generar, en consecuencia, una nueva regulación vinculante. Asimismo, Kohen agrega que la buena fe resulta exigible durante las negociaciones - como también en los otros medios de solución pacífica-y advierte que las acciones realizadas con el único propósito de desviar su curso u obtener tiempo, sin intención de resolver la controversia, no permite sostener a futuro que el tiempo ha consolidado su pretensión (Kohen, 1997 pp. 41 y 159).

En definitiva, la buena fe constituye uno de los principios básicos que rige el establecimiento y cumplimiento de las obligaciones jurídicas, sin importar su fuente, tal como lo señaló la CIJ en el Asunto de los Ensayos Nucleares(67). Si la negociación en un caso concreto constituye una obligación probada por una de las partes de la controversia, la respuesta aparece obvia: la buena fe resulta no solo manifiestamente aplicable, sino exigible.

Finalmente, nadie discute la existencia de la responsabilidad precontractual o la culpa in contrahendo como principio general de derecho. En ese sentido ¿es posible que las legítimas expectativas de una parte - sumado al progreso de las negociaciones- no genere siquiera la obligación de exigir la buena fe en las negociaciones?

Lo anterior no significa desconocer que, al negociar la solución de la controversia, alguna de las partes evite realizar un procedimiento de análisis exhaustivo o detallado y que ello limite la pluralidad de conducción u opción de métodos. Sin embargo, entendemos que es posible reclamar, éticamente, que las partes negocien con real seriedad.

(67) Cfr. Nuclear Tests (New Zealand v. France), Judgment, I.C.J. Reports 1974 (p. 268, párr. 46). 
EL PROCESO NEGOCIADOR EN EL DERECHO INTERNACIONAL CONTEMPORÁNEO: DE LA ELABORACIÓN DE ACUERDOS A LA SOLUCIÓN DE CONTROVERSIAS INTERNACIONALES

- LEOPOLDO M. A. GODIO (PP. 495-526)

\section{Reflexiones finales}

La historia del derecho internacional contemporáneo comprende muchos éxitos, pero también fracasos y la solución pacífica de controversias no constituye una excepción al respecto. En nuestro el examen, la negociación se revela como un proceso ampliamente utilizado y flexible, que no se limita a la regulación de las conductas futuras de las partes regidas por el derecho internacional o crear organizaciones internacionales, sino que también resulta un esencial medio de solución de diferendos apto para distintas etapas de aquel: al inicio para acordar una cláusula compromisoria que someta la controversia a un tribunal internacional o al arbitraje; durante el pleno desarrollo, utilizándole en paralelo a otro método; e incluso luego de un laudo o sentencia, con el objeto de cumplir u observar la ejecución de aquella.

La contribución positiva de la negociación como medio de solución de controversias internacionales no puede clasificarse por su costo - presumiblemente menor en términos de flexibilidad y economía, una vez alcanzado el acuerdoni cuantificarse estadísticamente, debido a la confidencialidad que presenta en ocasiones. Incluso, tampoco se la puede valorar desde lo cualitativo, ya que considerar la importancia de su utilización depende de la controversia puntual y su gravedad, razón por la cual, en definitiva, el beneficiario a considerar no debería ser otro que la comunidad internacional y en función de los objetivos de la Carta de las Naciones Unidas, a la luz de la conducta asumida por las partes interesadas.

Asimismo, debe tenerse presente que la utilización de la opción jurisdiccional no significa, necesariamente, el fracaso de la negociación como estrategia, ya que tal como ocurrió en las controversias de Chile y la UE, así como más recientemente entre Ecuador y Colombia, a veces los Estados participan en litigios sin buscar necesariamente una compensación, una sentencia o una medida provisional, sino "jugar" con las reglas autorizadas a partir del artículo 2 (3) y 33 de la Carta y el derecho convencional aplicable para obtener un reconocimiento claro y favorable sobre un punto determinado, que puede servir como guía para una conducta futura para las partes (Lowe, 2007, p. 239).

A pesar que la CIJ no haya reconocido la existencia de una "obligación de negociar" entre Bolivia y Chile - ante la ausencia de pruebas por parte del solicitante y la inexistencia de una obligación fundada en el derecho internacional general-, el tribunal destacó la disponibilidad de elección los medios de arreglo pacífico - lo que se traduce como una observancia de comportamiento, y no de resultado- pero también es posible señalar la existencia de un capital jurídico en otros asuntos, en los cuales reconoció la importancia de entablar "negociaciones significativas" y continuarlas con miras a concluir acuerdos, aunque no signifique la obligación de alcanzarlos. 
Este carácter "significativo" es donde la buena fe equivale a desarrollo de negociaciones sin rupturas injustificadas, aplazamientos anormales, inobservancias de procedimientos o negativas sistemáticas a considerar propuestas o intereses de la otra parte. La negociación de buena fe resulta exigible - o al menos clara - en cuanto a que su observancia posee fuerza como principio general de derecho, una línea de conducta que rige todo obrar de los Estados y es pasible de reclamo mediante las opciones autorizadas por el derecho internacional.

Finalmente, la lección de la controversia entre Bolivia y Chile puede ser contextualizada en el sentido que la decisión de un tribunal no determina -necesariamente - al "ganador", sino que le otorga a una de las partes una sentencia que expresa quien "debería ser el ganador" de la controversia. La disputa de fondo entre las partes aún persiste y es de esperar que en algún momento se inicie - cuando cambien los vientos políticos de la región en forma propicia - una dura y creativa negociación en la búsqueda de una solución satisfactoria que, en definitiva, no es otra cosa que el fin de una etapa para desplegar otras opciones de arreglo, con diferentes configuraciones (Lowe, 2007: 238) y, en ese sentido, la lección de Timor Oriental a Australia - cuyo acuerdo fue alcanzado antes de la publicación del informe de la comisión de conciliación en 2018, superando la posición inflexible australiana - representa un excelente ejemplo del cambio necesario para alcanzar un posterior y equitativo arreglo.

\section{Bibliografía}

Barboza, J. (2008). Derecho Internacional Público. 2da. Ed. Buenos Aires: Zavalía.

Caminos, H. (2013). The Growth of Specialized International Tribunals and the Fears of Fragmentation of International Law. En N. Boschiero; T. Scovazzi; C. Pitea y C. Ragni (eds.), International Courts and the Development of International Law: Essays in Honour of Tullio Treves (pp. 55-64). The Hague: Springer.

Davérède, A. L. (2012). Negotiations, Secret. En R. Wolfrum (ed.), The Max Planck Encyclopedia of Public International Law. Oxford: Oxford University Press.

Diez de Velasco Vallejo, M. (2013). Instituciones de Derecho Internacional Público, $18^{\circ}$ Ed. Madrid: Tecnos.

Godio, L. M. A. (2019). Las actividades militares como excepciones facultativas al sistema de solución de controversias de la Convención de las Naciones Unidas sobre el Derecho del Mar de 1982. En L. M. A. Godio (coord.), El sistema de solución de controversias de la Convención de las Naciones Unidas sobre el Derecho del Mar: contribuciones de su experiencia (pp. 435-469). Buenos Aires: Eudeba. 
EL PROCESO NEGOCIADOR EN EL DERECHO INTERNACIONAL CONTEMPORÁNEO: DE LA ELABORACIÓN DE ACUERDOS A LA SOLUCIÓN DE CONTROVERSIAS INTERNACIONALES

- LEOPOLDO M. A. GODIO (PP. 495-526)

Godio, L. M. A. (2014). La contribución de los métodos de solución pacífica de controversias a la estabilidad de las relaciones internacionales. Anuario Argentino de Derecho Internacional, XXIII (pp. 287-336).

Godio, L. M. A. (2013). Algunas consideraciones respecto de las controversias pesqueras actuales y el uso de la tecnología satelital. La experiencia de los tribunales internacionales. El Derecho, edición del 25 de septiembre de 2013 (pp. 1-6).

Hakapää, K. (2012). Negotiation. En R. Wolfrum (ed.), The Max Planck Encyclopedia of Public International Law. Oxford: Oxford University Press.

Keohane, R. y Nye, J. (1988). Poder e interdependencia. La política mundial en transición. Buenos Aires: Grupo Editor Latinoamericano.

Kohen, M. G. (1997). Possession Contestée et Souveraineté Territoriale. Paris: Presses Universitaires de France.

Lowe, V. (2007). The interplay between negotiation and litigation in international dispute settlement. En T. M. Ndiaye y r. Wolfrum (eds.), Law of the Sea. Environmental Law and Settlement of Disputes: Liber Amicorum Judge Thomas A. Mensah (pp. 235-247). Leiden/Boston: Martinus Nijhoff.

Martínez, M. C. (2019). El caso del pez espada entre la UE y Chile y su resolución ¿una vinculación temática en aras del acuerdo de libre comercio? En L. M. A. Godio (comp.), El sistema de solución de controversias de la Convención de las Naciones Unidas sobre el Derecho del Mar: contribuciones de su experiencia (pp. 601-627). Buenos Aires: Eudeba.

Orellana, M. A. (2001). The EU and Chile suspend the swordfish case proceedings at the WTO and the International Tribunal of the Law of the Sea. ASIL Insights, February 2001.

Pastor Ridruejo, J. A. (2011). Curso de Derecho Internacional Público y Organizaciones Internacionales, 15ta. Ed. Madrid: Tecnos.

Pezzano, L. (2016). La obligación de negociar y la cuestión Malvinas. Buenos Aires: CLACSO.

Rodríguez, F. D. (2019). Conciliación obligatoria: el caso de Timor Oriental y Australia. En L. M. A. Godio (comp.), El sistema de solución de controversias de la Convención de las Naciones Unidas sobre el Derecho del Mar: contribuciones de su experiencia (pp. 143-168). Buenos Aires: Eudeba. 
Rousseau, C. (1966). Derecho Internacional Público, $3^{\text {a }}$ Ed. Barcelona: Ediciones Ariel.

Seara Vázquez, M. (2005). Derecho Internacional Público. México DF: Porrúa.

Sørensen, M. (1994). Manual de Derecho Internacional Público, 5ta. reimpresión. México DF: Fondo de Cultura Económica.

Tanzi, A. M. (2017). International Law. A concise introduction. Bologna: Bonomo-Wouters Kluwer Italia.

Waltz, K. N. (2006). Teoría de la política internacional. Buenos Aires: Grupo Editor Latinoamericano.

\section{Legislación y documentos}

Convención de Viena sobre la Sucesión de Estados en Materia de Tratados, adoptada el 23 de agosto de 1978. United Nations Treaty Series, Vol. 1946.

Tratado Americano de Soluciones Pacíficas del 30 de abril de 1948.

Convención sobre el Comercio de Tránsito de los Estados sin Litoral, adoptada el 8 de julio de 1965. United Nations Treaty Series, Vol. 597.

Convención de Viena sobre el Derecho de los Tratados, adoptada el 23 de mayo de 1969. United Nations Treaty Series, Vol. 1155.

Convención de las Naciones Unidas sobre el Derecho del Mar, adoptada el 30 de abril de 1982. United Nations Treaty Series, Vol. 1833.

Declaración de Manila sobre el Arreglo de Controversias Internacionales. Resolución AG A/RES/37/10 (XXXVI), 15 de noviembre de 1982.

Convención de las Naciones Unidas contra el Tráfico Ilícito de Estupefacientes y Sustancias Psicotrópicas de 1988.

Principios y directrices para las negociaciones internacionales. Resolución 53/101 de la Asamblea General de las Naciones Unidas. Resolución AG 53/101, adoptada el 8 de diciembre de 1998 (Doc. A/RES/53/101).

Acuerdo de Asociación Chile-UE, del 18 de noviembre de 2002.

Convención de las Naciones Unidas contra la Corrupción, adoptada el 31 de octubre de 2003 (Doc. A/RES/58/422). 
Convención de las Naciones Unidas sobre las inmunidades jurisdiccionales de los Estados y de sus bienes, adoptada el 2 de diciembre de 2004 (Doc. A/ RES/59/38).

Treaty between Australia and the Democratic Republic of Timor-Leste establishing their maritime boundaries in the Timor Sea, $6^{\text {th }}$ March 2018.

\section{Informes}

Conciliation between The Democratic Republic of Timor-Leste and The Commonwealth of Australia, P.C.A., Decision on Compentence, 19 September 2016.

Conciliation between The Democratic Republic of Timor-Leste and The Commonwealth of Australia (Timor-Leste v. Australia), P.C.A., Report and recommendations of the compulsory conciliation commission between Timor-Leste and Australia on the Timor Sea, 9 May 2018.

\section{Jurisprudencia (ordenada cronológicamente)}

Corte Permanente de Justicia Internacional:

Mavrommatis Palestine Concessions (Greece v. United Kingdom), Judgment of 30 August 1924, Objection to the Jurisdiction of the Court, P.C.I.J., Series A, No. 2.

Free Zones of Upper Savoy and the District of Gex, Order of 19 August 1929, P.C.I.J., Series A, No. 22.

Railway Traffic between Lithuania and Poland, Advisory Opinion, 1931, P.C.I.J., Series A/B, No. 42.

Corte Internacional de Justicia:

South West Africa (Ethiopia v. South Africa; Liberia v. South Africa), Preliminary Objections, Judgment, I.C.J. Reports 1962 (p. 319).

North Sea Continental Shelf, Judgment, I.C.J. Reports 1969 (p. 3).

Fisheries Jurisdiction (United Kingdom v. Iceland), Merits, Judgment, I.C.J. Reports 1974 (p. 3).

Fisheries Jurisdiction (Federal Republic of Germany v. Iceland), Merits, Judgment, I.C.J. Reports 1974 (p. 175).

Nuclear Tests (New Zealand v. France), Judgment, I.C.J. Reports 1974 (p. 253). 
United States Diplomatic and Consular Staff in Tehran, Judgment, I.C.J. Reports 1980 (p. 3).

Delimitation of the Maritime Boundary in the Gulf of Maine Area, Judgment, I.C.J. Reports 1984 (p. 246).

Passage through the Great Belt (Finland v. Denmark), Provisional Measures, Order of 29 July 1991, I.C.J. Reports 1991 (p. 12).

Passage through the Great Belt (Finland v. Denmark), Order of 10 September 1992, I.C.J. Reports 1992 (p. 348).

Maritime Delimitation and Territorial Questions between Qatar and Bahrain, Jurisdiction and Admissibility, Judgment, I.C.J., Reports 1994 (p. 112).

Legality of the Threat or Use of Nuclear Weapons, Advisory Opinion, I.C.J. Reports 1996 (p. 226).

Arial Incident of 10 August 1999 (Pakistan v. India), Jurisdiction of the Court, Judgment, I.C.J. Reports 2000 (p. 12).

Armed Activities on the Territory of the Congo (New Application: 2002) (Democratic Republic of the Congo v. Rwanda), Jurisdiction and Admissibility, Judgment, I.C.J. Reports 2006 (p. 6).

Maritime Delimitation in the Black Sea (Romania v. Ukraine), Judgment, I.C.J. Reports 2009, (p. 61).

Pulp Mills on the River Uruguay (Argentina v. Uruguay), Judgment, I.C.J. Reports 2010 (p. 14).

Application of the International Convention on the Elimination of All Forms of Racial Discrimination (Georgia v. Russian Federation), Preliminary Objections, Judgment, I.C.J. Reports 2011 (p. 70).

Questions relating to the Obligation to Prosecute or Extradite (Belgium v. Senegal), Judgment, I.C.J. Reports 2012 (p. 422).

Aerial Herbicide Spraying (Ecuador v. Colombia), Order of 13 September 2013, I.C.J. Reports 2013 (p. 278).

Obligation to Negotiate Access to the Pacific Ocean (Bolivia v. Chile), Preliminary Objection, Judgment, I.C.J. Reports 2015 (p. 592). 
Obligations concerning Negotiations relating to Cessation of the Nuclear Arms Race and to Nuclear Disarmament (Marshall Islands v. India), Jurisdiction and Admissibility, Judgment, I.C.J. Reports 2016 (p. 255).

Obligations concerning Negotiations relating to Cessation of the Nuclear Arms Race and to Nuclear Disarmament (Marshall Islands v. Pakistan), Jurisdiction and Admissibility, Judgment, I.C.J. Reports 2016 (p. 552).

Obligations concerning Negotiations relating to Cessation of the Nuclear Arms Race and to Nuclear Disarmament (Marshall Islands v. United Kingdom), Preliminary Objections, Judgment, I.C.J. Reports 2016 (p. 833).

Obligation to Negotiate Access to the Pacific Ocean (Bolivia v. Chile), Judgment, I.C.J. Reports 2018 (p. 507).

Tribunal Internacional del Derecho del Mar:

Conservation and Sustainable Exploitation of Swordfish Stocks (Chile/European Union), Order of 16 December 2009, ITLOS Reports 2008-2010 (p. 13).

Fecha de recepción: 28-02-2021

Fecha de aceptación: 20-09-2021 
